\title{
PETROGRAFÍA DE LA ALFARERÍA ARQUEOLÓGICA DEL RÍO SALADO BONAERENSE
}

\section{PETROGRAPHY OF THE ARCHAEOLOGICAL POTTERY OF THE SALADO RIVER (PROVINCE OF BUENOS AIRES, ARGENTINA)}

\author{
M. Magdalena Frère ${ }^{1}$, M. Isabel González ${ }^{2}$, Débora Chan ${ }^{3}$, Myriam Flores ${ }^{4}$ \\ ${ }^{1}$ Instituto de Arqueología, FFyL UBA. E-mail: magdafrere@hotmail.com \\ ${ }^{2}$ Instituto de Arqueología, FFyL. UBA. E-mail: igonzale@filo.uba.ar \\ ${ }^{3}$ Área de Bioestadística. FCV. UBA. E-mail: deborachan@yahoo.com.ar \\ ${ }^{4}$ Área de Bioestadística. FCV. UBA. E-mail: mcflor@fvet.uba.ar
}

Presentado el: 22/08/2012 - Aceptado el: 13/11/2012

\section{Resumen}

En este trabajo se presentan los resultados obtenidos mediante el análisis estadístico multivariado de 50 cortes delgados de alfarería de sitios de la Depresión del río Salado provincia de Buenos Aires, con cronologías del Holoceno tardío. A través de estos análisis se determinaron similitudes y diferencias entre los conjuntos cerámicos. Además se consideraron los aspectos macroscópicos de los fragmentos y los ambientes de donde provienen ya sea lagunas permanentes, lagunas temporarias o cercanos al río. Las diferencias mineralógicas estarían señalando elecciones en las prácticas de los alfareros, quienes emplearon distintas arcillas e inclusiones con los que manufacturaron una amplia variedad de recipientes de diversas formas y tamaños.

Palabras claves: Cazadoress-recolectores-pescadores, Area de la Depresión del río Salado, Petrografía cerámica

\begin{abstract}
The pottery from sites located within the Salado River Basin (Province of Buenos Aires) is studied by means of a multivariate statistical analysis of 50 thin sections; the sites date from the Late Holocene. The analysis allowed to determine similarities and differences between the ceramic assemblages. The macroscopic aspects of the sherds were also considered, as well as their provenance environments, either permanent or temporary lakes, or close to the river. The mineralogical differences seem to indicate choices in the potters' practices in their use of different clays and in the use of temper for the manufacture of a broad variety of vessels of different shapes and sizes.
\end{abstract}

Keywords: Hunter-gatherer-fishers, Salado River Basin, Ceramic petrography 


\section{Introducción}

El objetivo de este trabajo es identificar algunos aspectos de la producción alfarera. Asimismo, determinar similitudes o diferencias entre los conjuntos cerámicos provenientes de distintos sitios de la Depresión del río Salado, todos ellos con cronologías del Holoceno tardío (Figura 1). Estas piezas pertenecen en su totalidad a grupos cazadores - recolectores - pescadores y provienen de sitios arqueológicos que constituyeron campamentos de actividades múltiples donde una de las prácticas primordiales fue la manufactura de alfarería. Estos sitios fueron ocupados durante largos períodos. Muestran evidencias de las etapas iniciales de la manufactura (masas de arcillas y rollos cocidos), que junto con la presencia de recursos locales (barros y combustible), apoyan el planteo de una producción local de vasijas de cerámica y el transporte de materias primas (pigmentos colorantes) desde Tandilia, distante unos 250 Km (González 1991, 2005)

En este artículo se presentan los estudios petrográficos de 50 cortes delgados de alfarería correspondientes a 13 sitios sobre los que se aplicó un análisis estadístico multivariado. Estas muestras se seleccionaron considerando como criterios: la ubicación de los yacimientos dentro del ambiente de humedal, cercano a lagunas permanentes, a lagunas temporarias o al río. Se consideran además aspectos macroscópicos de los fragmentos, como las partes de las vasijas representadas, sus espesores, el acabado de la superficie y la presencia de decoración. También, se describen las diferentes elecciones realizadas por los alfareros para manufacturar sus vasijas.

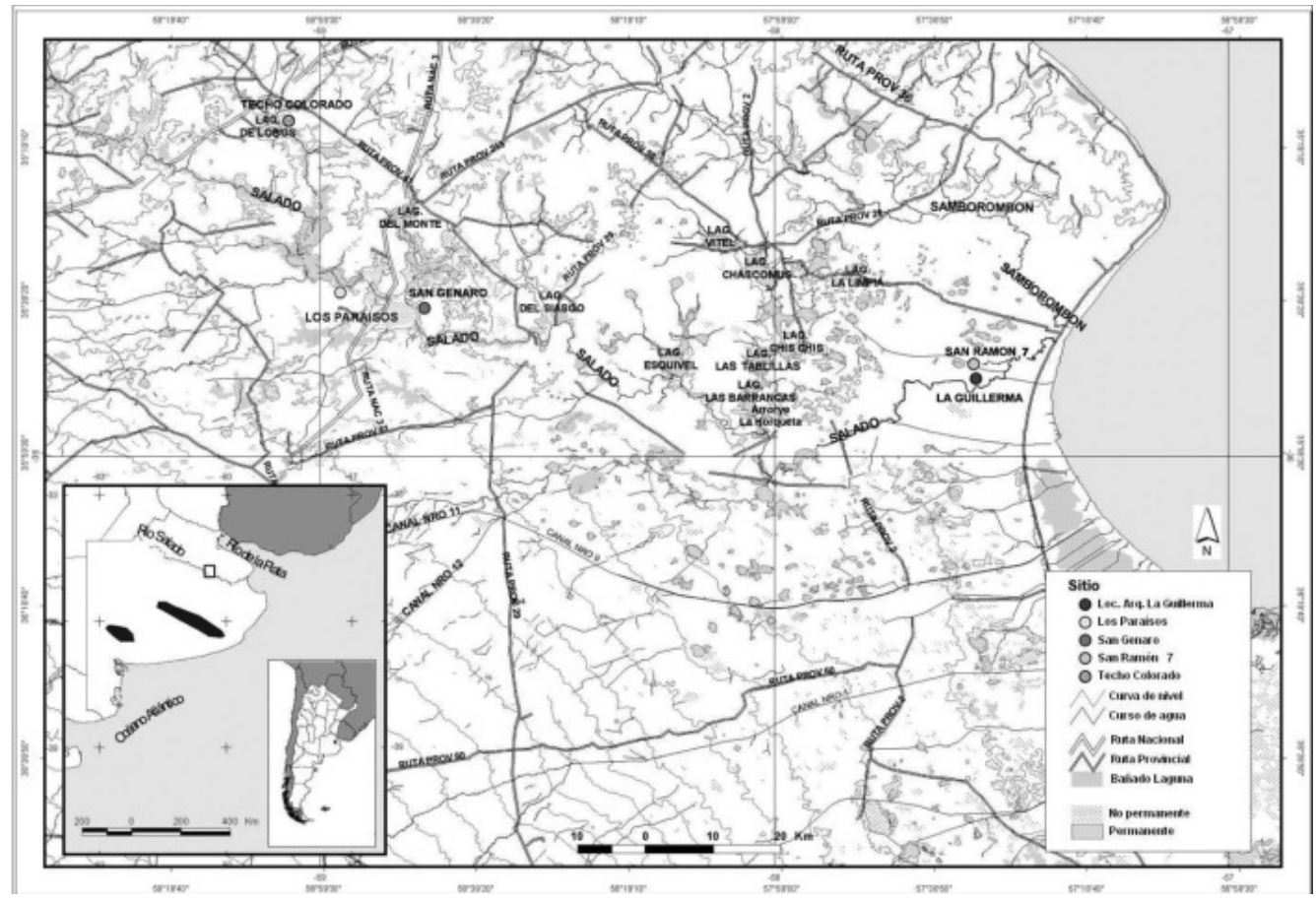

Figura 1 Mapa con la ubicación de los sitios arqueológicos estudiados 


\section{Antecedentes de estudios petrográficos}

Para referirnos a los primeros estudios petrográficos en la subárea Pampa Húmeda debemos sin duda mencionar, entre los trabajos pioneros, los de Patricia Madrid (1997). Esta investigadora inició los estudios de láminas delgadas con el objetivo de conocer la composición mineralógica y la variabilidad regional, tendiente a discriminar grupos cerámicos y distribución inter e intrasitio a nivel espacial y temporal. Realizó sus estudios sobre fragmentos cerámicos provenientes de ocho sitios distribuidos en una línea de 200 $\mathrm{km}$ desde el sistema serrano de Tandilia hasta el sector central del sistema de Ventania, encontrándose la mayoría de estos sitios en la llanura Interserrana. La autora planteó seis agrupamientos surgidos de las variaciones en la frecuencia, tamaño y asociaciones de los minerales. Madrid observó que las muestras analizadas tenían en común la presencia de cuarzo, plagioclasas, riolita, ortoclasa, mica y piroxeno, entre todos estos el cuarzo era el más abundante. Estableció que en dos sitios arqueológicos (La Toma y Zanjón Seco 2) se usaron pastas con orígenes diferentes y en otros determinó la presencia de varios tipos de pastas. En ninguno de estos ocho sitios se hallaron indicadores de las etapas iniciales de la producción alfarera.

La continuidad de este tipo de estudios en la llanura bonaerense puede consultarse en un trabajo reciente referido a la caracterización petrográfica de cerámica de las sierras de Tandilia (Mazzanti y Porto López 2007). A nivel de escala regional, estos investigadores, señalaron la existencia de semejanzas entre la cerámica de la Depresión del Salado y la de los sitios de las sierras de Tandilia. Observaron que las inclusiones mayoritarias eran en general las mismas pero con diferencias en aspectos tecnológicos como en la porosidad y en el agregado de tiesto molido. En ambos casos las pastas contenían restos de vegetales carbonizados que pudieron estar presentes naturalmente en las arcillas.

En la Depresión del río Salado, los estudios de alfarería que venimos desarrollando marcan un interés por reconocer las características de las materias primas involucradas en la cadena operativa de la elaboración de vasijas. Dimos inicio a este tema en el año 1991 con los primeros análisis microscópicos de cortes delgados de fragmentos arqueológicos y de muestras experimentales. En esa ocasión contamos con la colaboración de Beatriz Cremonte que efectuó la caracterización de las pastas (González de Bonaveri 1991, González 2005). Estos estudios petrográficos fueron ampliados a lo largo del desarrollo de nuestro proyecto de investigación (González de Bonaveri et al. 2000, González et al. 2009). Paralelamente en nuestro diseño de investigación arqueométrica incluimos los análisis químicos, acudiendo a la técnica de cromatografía de gases y espectrometría de masa, para determinar la presencia de residuos grasos en las muestras cerámicas (González de Bonaveri y Frére, 2002, 2004, Frére et al. 2010). Asimismo, continuamos con el desarrollo del programa de experimentación que contribuye al conocimiento tecnológico sobre la producción, decoración y usos de las alfarerías bonaerenses (González de Bonaveri et al. 2000, Francese 2000, Frère et al. 2004, González et al. 2007, González y Frère 2009, 2010).

En resumen, al avanzar en el desarrollo de nuestro proyecto marco hemos identificado numerosos sitios arqueológicos en los partidos de San Miguel del Monte, Lobos y Chascomús y recuperamos abundante material cerámico indígena con el objetivo final de reconstruir los procesos socioculturales ocurridos en estos espacios durante el Holoceno tardío. 


\section{Aspectos sedimentológicos del área de estudio}

En la llanura pampeana se reconocen diferencias sedimentológicas, evidenciadas por la composición de la cubierta sedimentaria más superficial, así como fisiográficas y geomorfológicas manifestadas a través de las variaciones exhibidas por las redes de drenaje y las formas del paisaje. Teniendo en cuenta estas diferencias, en la provincia de Buenos Aires se distinguen, entre otras áreas, la pampa ondulada, la pampa deprimida y la pampa alta o pampa interserrana (Zárate 2009 y referencias allí citadas). La pampa deprimida que comprende la cuenca hídrica del río Salado, donde se ubican los sitios aquí trabajados, se caracteriza por la dominancia de gradientes muy bajos, drenaje superficial deficiente y la presencia de geoformas eólicas (Zárate 2009).

En la caracterización del loess pampeano Teruggi (1957) y González Bonorino (1965) reconocen la presencia de cuarzo, plagioclasa de origen volcánico, feldespatos alcalinos, vidrio volcánico y abundantes fragmentos líticos, fundamentalmente volcánicos.

En este artículo consideramos también recientes estudios geológicos de la pampa deprimida efectuados por Dangavs y colaboradores. Estos trabajos incluyen aspectos sedimentológicos y geomorfológicos realizados en perfiles de las localidades de Chascomús, Lobos y San Miguel del Monte (Dangavs 1979; Dangavs 2005 a y b; Dangavs et al. 1991, 2003, Dangavs y Reynaldi 2008).

Para San Miguel del Monte, Dangavs y Reynaldi (2008) han podido establecer la historia geológica cuaternaria en la cubeta de la laguna Cerrillos del Medio, que se encuentra próxima a los sitios Los Cerrillos y San Genaro. Los sedimentos que corresponden al Holoceno se caracterizan por presentar componentes volcaniclásticos, escaso yeso y ausencia de carbonatos en la fracción arena mediana a limo grueso. En la fracción arena fina domina el vidrio volcánico acompañado de feldespato alcalino, líticos volcánicos -que brindan aspecto rojizo al sedimento-, también son frecuentes la plagioclasa, el cuarzo y los minerales pesados. En la arena muy fina el orden de abundancia es el siguiente: plagioclasa, cuarzo, feldespato alcalino, líticos volcánicos, vidrio volcánico y minerales pesados. En el limo grueso son muy abundantes los minerales pesados: opacos, en su mayoría magnetita, anfíboles, piroxenos, micas y epidotos. Los restos biológicos son muy escasos y corresponden a fragmentos de conchillas, huesitos rodados y fitolitos.

En cuanto a la estratigrafía y la geología de la localidad La Guillerma en Chascomús se reconocen distintas unidades estratigráficas cuaternarias (González de Bonaveri y Zárate 1993/94; González 2005: 73-75): UNIDAD 1: limos arcillo-arenosos, castaño rojizos, macizos, planos de estratificación horizontal discontinuos, muy poco definidos; acumulaciones de carbonato de calcio friables a pulvurulentas. UNIDAD 2: arenas muy finas arcillo-limosas que pasan hacia arriba a limos arcillosos castaño-verdosos. UNIDAD 3: arenas muy finas, limosas y limolitas arcillosas con estratificación horizontal; incluye un nivel de ceniza volcánica y bancos de Littoridinas y otros moluscos. UNIDAD 4: nivel de arenas limo arcillosas con fragmentos de caracoles dulceacuícolas y de tiestos cerámicos en la base apoyado en discordancia erosiva sobre la unidad 3 o la unidad 2. UNIDAD 5: depósito aluviales recientes del río Salado. Además contamos con caracterizaciones mineralógicas de la fracción arcillosa de sedimentos que se efectuaron mediante Difracción de Rayos X (DRX). Las muestras analizadas por Cecilia Camilión señalaron la presencia de caolinita, illita y esmectita en sedimentos de un 
sitio de la localidad La Guillerma (LG5) (González 2005). A su vez, Dangavs (2009) describe los sedimentos del arroyo La Horqueta, cercanos al sitio Las Tablillas (Chascomús). En estos sedimentos, la fracción de arena mediana es mínima y se caracteriza por agregados pelíticos, yeso, concreciones de hierro-manganeso, cuarzo, calcedonia, plagioclasa y feldespato potásico. En la arena fina predomina el vidrio volcánico en trizas límpidas o rellenas con arcilla, acompañado por abundantes feldespatos potásicos y líticos volcánicos que brindan coloración anaranjada a rojiza al sedimento, también son frecuentes las micas y otros minerales pesados. La mineralogía de la arena muy fina está determinada por plagioclasa, cuarzo, feldespato potásico, líticos volcánicos, vidrio volcánico y minerales pesados. En el limo grueso, además de los minerales livianos, son muy abundantes los pesados: micas, anfíboles, piroxenos, epidotos y minerales opacos, siendo mayoría la magnetita.

La laguna de Lobos se encuentra asentada en depósitos sedimentarios cuaternarios. Según Dangavs y colaboradores (1991) se reconocen 3 unidades litoestratigráficas la Formación Ensenada, que es una unidad de extensión continental y constituye la roca base del paisaje actual. Está compuesta por limos loessoides entoscados y loess algo arenoso. La mineralogía
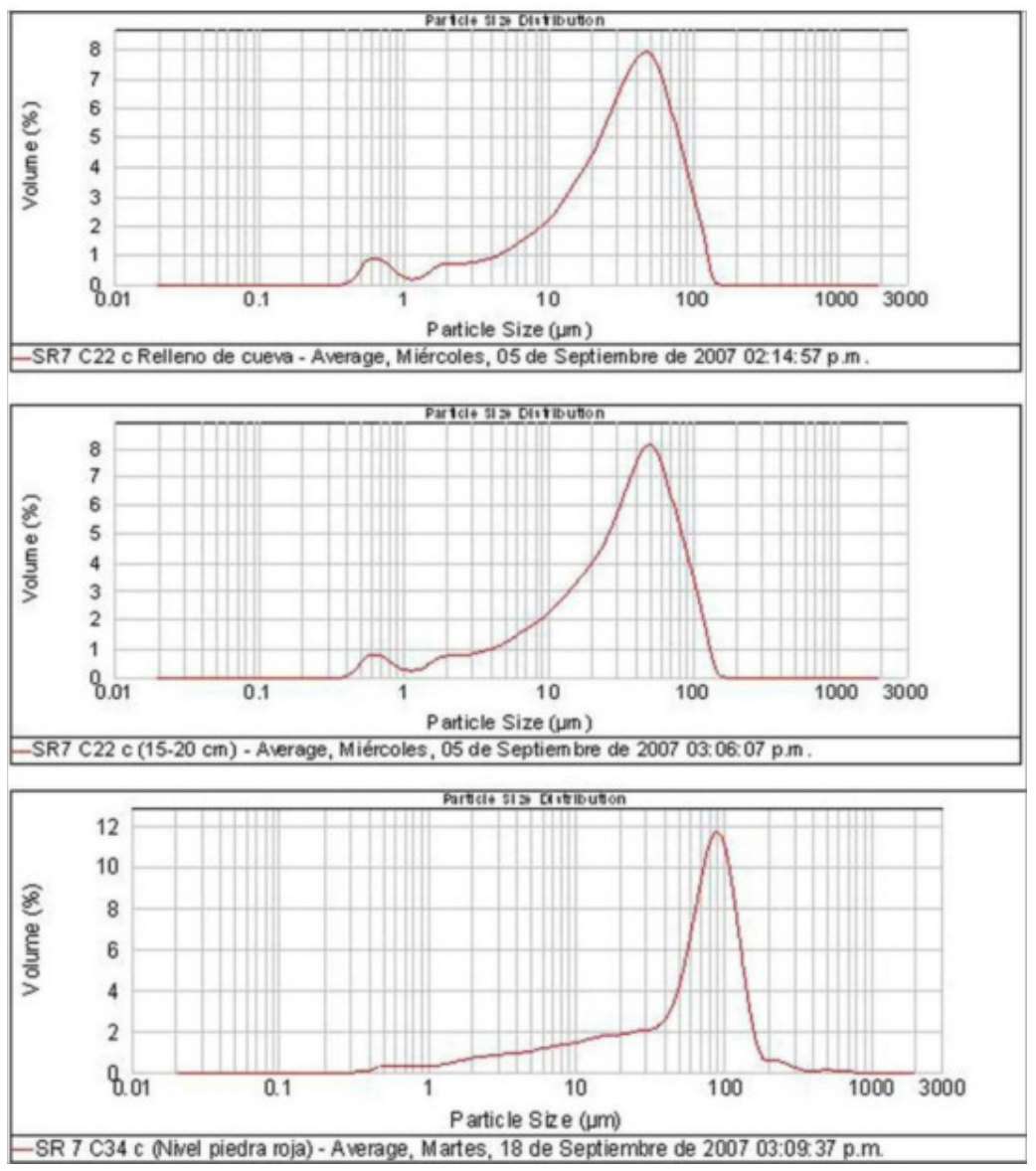

Figura 2 a. Estudios granulométricos de los sitios San Ramón 7 (SR7) 

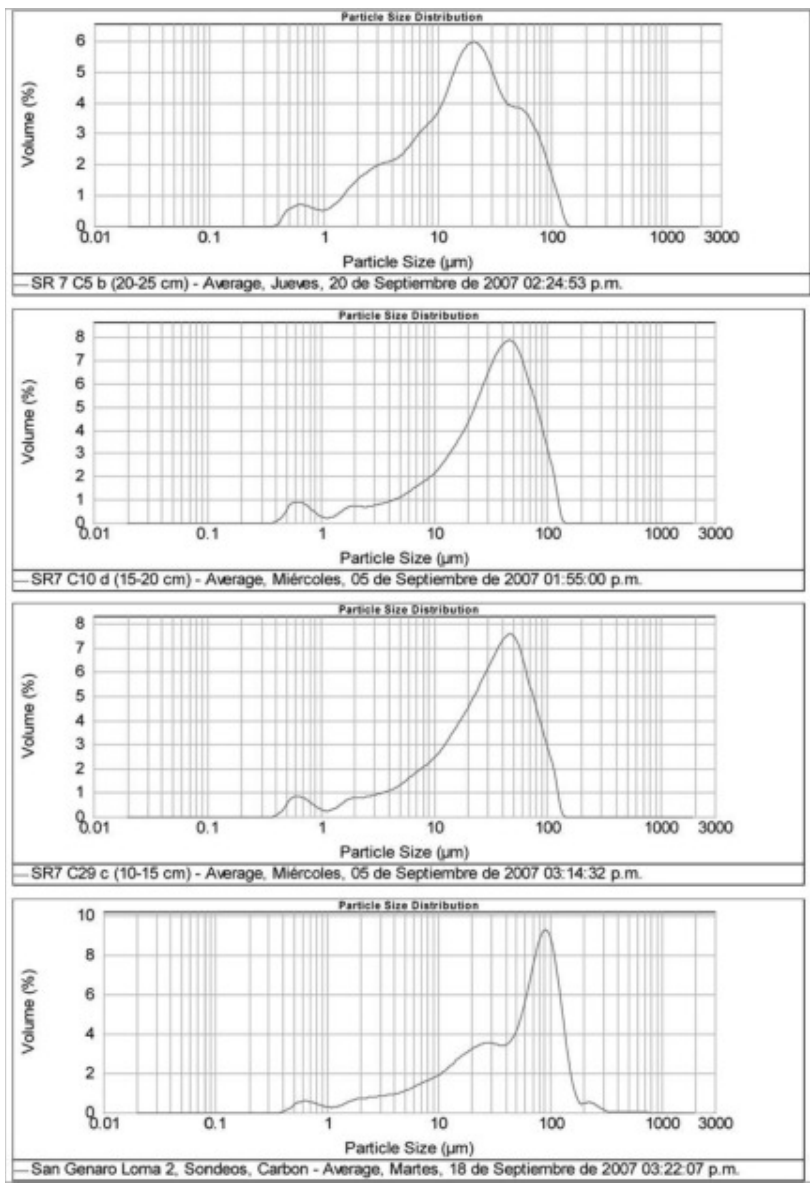

Figura 2b. Estudios granulométricos de los sitios San Ramón 7 (SR7) y San Genaro (SG)

de la fracción arena indica el predominio en los tamaños mayores a 0,25 $\mathrm{mm}$. En las fracciones arena fina y muy fina, el vidrio volcánico aparece en trizas límpidas y su abundancia no supera el $20 \%$. Entre los minerales dominan la plagioclasa, el cuarzo, y el feldespato potásico. De los minerales pesados los más abundantes son la muscovita y biotita. En la Formación Buenos Aires, la mineralogía de la fracción arena indica predominio de vidrio volcánico, el cuarzo es común en las muestras y aparece redondeado a bien redondeado. También se encuentran plagioclasas redondeadas y entre los minerales pesados se mencionan biotita, muscovita, anfíboles y piroxenos. Los depósitos de la Formación La Postrera son de carácter loéssicos, tienen textura limo arenosa y color predominantemente castaño claro. En todas las muestras este loess tiene una composición vitroclástica en el tamaño arena fina y volcaniclástica en las menores. Cuando aparecen tamaños mayores a la arena fina, éstos son a expensas de tosquillas, concreciones de hierro-manganeso y agregados débilmente cementados por arcillas (Dangavs et al. 1991).

Para analizar específicamente los sedimentos de algunos de los sitios aquí tratados se efectuaron estudios granulométricos. Con este fin, en el Laboratorio de Sedimentología del Instituto de Ciencias de la Tierra y Ambientales de La Universidad Nacional de La Pampa se analizaron siete muestras de sedimentos. Seis ejemplares corresponden al Sitio San 
Ramón 7 (SR7) y señalan que los mismos están dominados por sedimentos compuestos por arena fina y limo grueso-limo mediano. La muestra restante, procedente del sitio San Genaro (Cerrillos del Medio, San Miguel del Monte), presenta una mayor participación de limo medio además del limo grueso (Figura 2 a y b).

\section{Materiales y Métodos}

Las 50 muestras analizadas (tabla 1 y 2 ) corresponden a sitios de la cuenca inferior y media del río Salado. Cinco de ellas provienen de recolección de superficie de sitios cercanos a lagunas permanentes de esta cuenca (Las Tablillas, El Burro, Chis-Chis), o laguna temporaria (Los Cerrillos), veinticinco corresponden a sitios excavados ubicados en las cercanías de lagunas permanentes (Techo Colorado, La Limpia y Vitel) o temporarias (San Ramón 7) y veinte muestras de sitios excavados vinculados al curso del río Salado (localidad arqueológica La Guillerma, Los Paraísos y San Genaro). Por otro lado, en los fragmentos analizados se consideraron los espesores, la parte de la vasija representada -ya sea cuerpo o borde- en un caso se analizó un fragmento de rollo o chorizo. Con respecto a los espesores de las muestras se considera delgados a los fragmentos con espesores inferiores a $5.2 \mathrm{~mm}$, medianos los comprendidos entre 5.2 a $8 \mathrm{~mm}$ y gruesos a los mayores a $8 \mathrm{~mm}$. Teniendo en cuenta la decoración presente en los tiestos consignamos la presencia de decoración incisa o pintada. En cuanto al acabado de la superficie señalamos la presencia o no de corrugado.

Los análisis de los fragmentos se realizaron con lupa binocular (aumentos: 8x a 40x) y los cortes delgados fueron estudiados ${ }^{1}$ utilizando un microscopio de Polarización (aumentos: $35 x$ a $1000 x)$.

\begin{tabular}{|c|c|c|}
\hline Sitio & $\begin{array}{c}\text { Cantidad de } \\
\text { muestras }\end{array}$ & Localidad \\
\hline $\begin{array}{l}\text { Techo Colorado } \\
\text { (TCol) }\end{array}$ & 2 & Lobos \\
\hline $\begin{array}{l}\text { Laguna Vitel } \\
\text { (VS) }\end{array}$ & 2 & Chascomús \\
\hline El Burro (LEB) & 1 & Chascomús \\
\hline $\begin{array}{l}\text { Las Tablillas } \\
\text { (LT) }\end{array}$ & 2 & Chascomús \\
\hline La Limpia (LL) & 1 & Chascomús \\
\hline $\begin{array}{l}\text { La Guillerma 1 } \\
\text { (LG1) }\end{array}$ & 6 & Chascomús \\
\hline $\begin{array}{l}\text { La Guillerma } 4 \\
\text { (LG4) }\end{array}$ & $\overline{4}$ & Chascomús \\
\hline $\begin{array}{l}\text { La Guillerma } 5 \\
\text { (LG5) } \\
\end{array}$ & 7 & Chascomús \\
\hline $\begin{array}{l}\text { La Guillerma } \\
\text { Ñandú (LGÑ) }\end{array}$ & 1 & Chascomús \\
\hline $\begin{array}{l}\text { San Ramón 7 } \\
\text { (SR7) }\end{array}$ & 20 & Chascomús \\
\hline $\begin{array}{l}\text { Los Paraísos } \\
\text { (LP) }\end{array}$ & 3 & $\begin{array}{c}\text { San Miguel del } \\
\text { Monte }\end{array}$ \\
\hline $\begin{array}{l}\text { Los Cerrillos } \\
\text { (LC) }\end{array}$ & 2 & $\begin{array}{c}\text { San Miguel del } \\
\text { Monte }\end{array}$ \\
\hline $\begin{array}{l}\text { San Genaro } \\
\text { (SG) }\end{array}$ & 1 & $\begin{array}{c}\text { San Miguel del } \\
\text { Monte }\end{array}$ \\
\hline
\end{tabular}

Tabla 1. Cantidad de muestras 


\begin{tabular}{|c|c|c|c|c|c|c|}
\hline MUESTRA & Ambiente & $(\mathrm{mm})$ & vasija & Incisa & Pintada & corrugada \\
\hline TCol S1 & laguna & 9 & cuerpo & No & No & No \\
\hline TCol S2 c5 & laguna & 8 & borde & $\mathrm{Si}$ & No & No \\
\hline LC 2 & laguna temp & $7,9-8,1$ & borde & $\mathrm{Si}$ & No & No \\
\hline LC 3 & laguna temp & 8,4 & cuerpo & No & No & No \\
\hline VS A4 & laguna & 6 & cuerpo & No & No & No \\
\hline VS A2 & laguna & 4,7 & cuerpo & No & $\mathrm{Si}$ & No \\
\hline LEB 1 & laguna & 5 & cuerpo & No & No & No \\
\hline LT 80 & laguna & 7,5 & cuerpo & No & No & No \\
\hline LT 83 & laguna & $4,9-5,8$ & borde & $\mathrm{Si}$ & No & No \\
\hline LL 1 & laguna & 8,7 & cuerpo & No & No & No \\
\hline LG1 10.897 & río & 9,4 & cuerpo & No & No & $\mathrm{Si}$ \\
\hline LG1 6.005 & río & 7,1 & cuerpo & No & $\mathrm{Si}$ & No \\
\hline LG1 huaq & río & $7,9-10,6$ & borde & No & $\mathrm{Si}$ & No \\
\hline LG1 2439 & río & 6 & cuerpo & No & No & No \\
\hline LG1 N IX a & río & 5,2 & cuerpo & No & No & No \\
\hline LG1 5076 & río & 6,2 & borde & $\mathrm{Si}$ & No & No \\
\hline LG4 421 & río & 6,1 & cuerpo & No & $\mathrm{Si}$ & No \\
\hline LG4 1371 & río & 10,1 & borde & No & No & $\mathrm{Si}$ \\
\hline LG5 1285 & río & 10,8 & cuerpo & No & No & $\mathrm{Si}$ \\
\hline LG5 BIXa C10 & río & $7,4-11,5$ & borde & $\mathrm{Si}$ & $\mathrm{Si}$ & No \\
\hline LG5 97 & río & $20,7-20,2$ & rollo & No & No & No \\
\hline LG5 1.905 & río & 6,1 & cuerpo & No & No & No \\
\hline LG5 2.514 & río & 5,2 & borde & $\mathrm{Si}$ & $\mathrm{Si}$ & No \\
\hline LG5 607 a & río & 7,7 & cuerpo & No & No & No \\
\hline LG5 607 b & río & 7,7 & cuerpo & No & No & No \\
\hline LGÑ BRRS & río & 15,5 & cuerpo & No & No & $\mathrm{Si}$ \\
\hline SR7 4a 2 & laguna temp & 4,5 & borde & $\mathrm{Si}$ & No & No \\
\hline SR74a4 & laguna temp & 6 & cuerpo & $\mathrm{Si}$ & No & No \\
\hline SR7 4a 6 & laguna temp & 9 & cuerpo & No & No & No \\
\hline SR7 4b 1 & laguna temp & 8,5 & cuerpo & No & No & No \\
\hline SR7 4b 4 & laguna temp & 4,5 & cuerpo & No & No & No \\
\hline SR7 4b9 & laguna temp & 6,2 & cuerpo & $\mathrm{Si}$ & No & No \\
\hline SR7 4b 12 & laguna temp & 6 & borde & $\mathrm{Si}$ & No & No \\
\hline SR7 4c 1 & laguna temp & 6,5 & cuerpo & No & No & No \\
\hline SR7 4d 1 & laguna temp & 6 & cuerpo & $\mathrm{Si}$ & No & No \\
\hline SR7 4d 2 & laguna temp & 4,1 & cuerpo & $\mathrm{Si}$ & No & No \\
\hline SR7 35 a1 & laguna temp & 7,5 & borde & $\mathrm{Si}$ & $\mathrm{Si}$ & No \\
\hline SR7 35 a2 & laguna temp & 9,1 & cuerpo & No & No & No \\
\hline SR7 35 a3 & laguna temp & 5,1 & borde & $\mathrm{Si}$ & No & No \\
\hline SR7 35 a4 & laguna temp & 5,9 & borde & No & No & No \\
\hline SR7 35 a5 & laguna temp & 5,9 & borde & $\mathrm{Si}$ & No & No \\
\hline SR7 $35 \mathrm{c1}$ & laguna temp & 5 & borde & No & No & No \\
\hline SR7 $35 \mathrm{~d} 3$ & laguna temp & 4,1 & borde & $\mathrm{Si}$ & No & No \\
\hline SR7 $35 \mathrm{~d} 4$ & laguna temp & 8,1 & cuerpo & No & No & No \\
\hline SR7 35 d4 (1) & laguna temp & 5,1 & borde & $\mathrm{Si}$ & $\mathrm{Si}$ & No \\
\hline SR7 35 d5 & laguna temp & 6,1 & cuerpo & $\mathrm{Si}$ & No & No \\
\hline LP 13 & río & 4 & cuerpo & No & No & No \\
\hline LP 24 & río & 3,9 & borde & $\mathrm{Si}$ & No & No \\
\hline LP 26 & río & 6,9 & cuerpo & No & No & No \\
\hline SG 16 & río & 5,9 & cuerpo & No & No & No \\
\hline
\end{tabular}

Tabla 2. Descripción de los fragmentos 
Se aplicaron, análisis de componentes principales, buscando establecer agrupamientos de la totalidad de las piezas. Asimismo se aplicaron análisis de correlación, test de la Mediana y test de Kruskal Wallis (KW) para establecer relaciones entre las distintas clasificaciones logradas (Seber 1984; Cuadras 1991; Bensmail y Celeux 1997; Tibshirani et al. 2001; Di Rienzo et al. 2009).

\section{Análisis de los datos}

Ahora mencionaremos algunas de las características macroscópicas de los fragmentos de alfarería estudiados. Con respecto a la átmosfera de cocción, varía entre oxidante completa o parcialmente oxidante ya que comprende los colores rojos y marrones y en pocos casos se observan colores que van de negro a gris evidenciando una cocción reductora. En cuanto al acabado de la superficie de estos tiestos, se han utilizado el alisado y el pulido y en la decoración están presentes las técnicas de incisión, engobe y pintura roja. Los espesores de las paredes de estos fragmentos son delgados y varían entre 4 y $8 \mathrm{~mm}$, sin embargo algunos tienen grosores mayores, cercanos a $15 \mathrm{~mm}$ y se presenta un caso de un rollo de arcilla que tiene más de $20 \mathrm{~mm}$ de espesor.

A continuación describiremos las características generales de la matriz o fondo de pasta, las cavidades y los antiplásticos. En la tabla 3 se señala la abundancia relativa de estas variables en cada fragmento.

La matriz arcillosa o fondo de pasta que proviene del loess pampeano, es muy homogénea en la muestra aquí analizada, es fina pero a su vez contiene limo y arenas finas. Está compuesta por minerales de arcilla, vidrio volcánico, microgránulos opacos de óxidos de Fe (hematita), biotita, diminutos cristales máficos (anfíbol y piroxeno), material criptocristalino (minerales que por el diminuto tamaño de grano, no alcanzan a distinguirse con microscopio petrográfico). Los componentes de la fracción limo, que se consideran parte de la matriz, son cuarzo, feldespato, litoclastos y vitroclastos. El color tiende a ser, en general, de castaño claro a castaño oscuro. La matriz es anisótropa, es decir, que la temperatura de cocción no alcanzó la vitrificación. Los elementos isótropos presentes en la matriz de todas las muestras son fragmentos de vidrio volcánico y vitroclastos de los sedimentos loessicos.

Las cavidades, espacios en la matriz ocupados por los poros y oquedades, son concentradores de tensiones, se forman entre las partículas sólidas y en algunos casos alrededor de una inclusión de tamaño grande como resultado de la contracción por pérdida de agua (Mari 1998: 21). Existen diversas causas que contribuyen a la formación de cavidades, muchas de ellas se forman en el proceso de amasado y en el de cocción (Cremonte y Bugliani 2009). Además hay otros factores (fluidos circulantes, meteorización química o física, suelos ricos en materia orgánica, etc.) que pueden modificar la porosidad original de los tiestos. Del mismo modo, el manipuleo para la preparación de los cortes delgados puede también contribuir a la modificación original de la presencia de cavidades (González et al. 2000: 221). En la muestra aquí analizada, las cavidades son micro y macroscópicas de formas variadas. Pueden encontrarse abiertas o cerradas a la superficie exterior. En algunos casos los poros están ocluidos por el tratamiento de la superficie, ya sea por alisado, pulido o aplicación de engobe. En la muestra bajo estudio $(n=50)$ más de la mitad de los fragmentos $(56 \%)$ tienen un contenido de poros del 10 al 25\%. 


\begin{tabular}{|c|c|c|c|}
\hline \multirow[t]{2}{*}{ MUESTRA } & MATRIZ & CAVIDADES & $\begin{array}{c}\text { INCLUSIONES } \\
\text { y/o CARGA }\end{array}$ \\
\hline & $(\%)$ & $(\%)$ & $(\%)$ \\
\hline TCol S1 & 50 & 25 & 25 \\
\hline TCol S2 c5 & 50 & 20 & 30 \\
\hline LC 2 & 45 & 35 & 20 \\
\hline LC 3 & 35 & 40 & 25 \\
\hline VS A4 & 50 & 25 & 25 \\
\hline VS A2 & 60 & 10 & 30 \\
\hline LEB 1 & 50 & 20 & 30 \\
\hline LT 80 & 40 & 25 & 35 \\
\hline LT 83 & 60 & 10 & 30 \\
\hline LL 1 & 55 & 20 & 25 \\
\hline LG1 10.897 & 35 & 50 & 15 \\
\hline LG1 6.005 & 35 & 50 & 15 \\
\hline LG1 huaq & 45 & 20 & 35 \\
\hline LG1 2439 & 45 & 40 & 15 \\
\hline LG1 N IX a & 30 & 50 & 20 \\
\hline LG1 5076 & 60 & 25 & 15 \\
\hline LG4 421 & 45 & 35 & 20 \\
\hline LG4 1371 & 70 & 10 & 20 \\
\hline LG5 1285 & 45 & 35 & 20 \\
\hline LG5 BIXa C10 & 60 & 20 & 20 \\
\hline LG5 97 & 55 & 25 & 20 \\
\hline LG5 1.905 & 40 & 35 & 25 \\
\hline LG5 2.514 & 35 & 30 & 35 \\
\hline LG5 607 a & 55 & 25 & 20 \\
\hline LG5 607 b & 60 & 20 & 20 \\
\hline LGÑ BRRS & 40 & 45 & 15 \\
\hline SR7 4a 2 & 55 & 30 & 15 \\
\hline SR74a4 & 50 & 25 & 25 \\
\hline SR7 4a 6 & 55 & 25 & 20 \\
\hline SR7 4b 1 & 50 & 35 & 15 \\
\hline SR7 4b 4 & 60 & 20 & 20 \\
\hline SR7 4b9 & 50 & 30 & 20 \\
\hline SR7 4b 12 & 45 & 25 & 30 \\
\hline
\end{tabular}

Tabla 3. Abundancia relativa. Los porcentajes de cavidades entre 45 y $50 \%$ pueden deberse a desprendimientos cuando se realiza el corte delgado. 
Se ha registrado la presencia de los siguientes materiales no plásticos: cuarzo (Q), plagioclasa $(\mathrm{Pl})$, feldespato alcalino $(\mathrm{Fa})$, hematita $(\mathrm{Hem})$, magnetita (Magn), mica (Mi), anfíbol $(\mathrm{An})$, vidrio volcánico $(\mathrm{V})$, fragmentos líticos $(\mathrm{Fl})$ y tiestos molidos $(\mathrm{TM})$. Con respecto a los Fl aclaramos que predominan las partículas de origen volcánico aunque también están presentes, en menor cantidad, fragmentos de origen sedimentario y metamórfico. Se debe tener en cuenta que los porcentajes de los materiales no plásticos presentados en la tabla 4 se refieren al 100\% de las inclusiones o carga. En este trabajo, tomamos esta decisión teniendo en cuenta los estudios mineralógicos del loess pampeano realizados por González Bonorino (1965: 103) quien presenta la distribución porcentual de los principales minerales de la fracción limo-arena fina en relación con la totalidad de los componentes clásticos.

A su vez, señalamos que la selección de los elementos que conforman la carga de estos tiestos (inclusiones minerales, litoclastos y tiesto molido) es de tipo bimodal. La mayor parte de los elementos corresponden a la fracción limo y arena muy fina y fina, propios del loess pampeano. La otra moda, que alcanza fracciones de arena muy gruesa se vincula con el agregado de tiesto molido. Este último es uno de los agregados intencionales que pudimos reconocer en este análisis, su uso permite un adecuado modelado de la arcilla. Los tiestos molidos son producto del reciclado de un material cerámico proveniente de piezas rotas o desechadas (DeBoer y Lathrap 1979; Mari 1998). Muchas veces su empleo tiene como finalidad dar mayor consistencia a la pasta. Debe cuidarse que su composición sea igual o por lo menos compatible con la del producto final (Mari 1998).

En la muestra pueden observarse grumos o pellets que forman parte de la materia prima, presentan aplastamientos, disposición subparalela de minerales y cavidades, como también bordes difusos y colores homogéneos con respecto al material que los contiene. Por el contrario el tiesto molido se distingue por una alineación diferencial de sus elementos no plásticos respecto a la pieza que los contiene, además tiene una coloración diferente a causa de la doble cocción al que fue sometido. Esto produce una contracción que permite observarlos con bordes definidos, separados de la matriz arcillosa que los contiene. Se establece, además, un acomodamiento de las partículas que componen la matriz arcillosa alrededor de estos tiestos molidos (Solá 2002).

Como puede verse en la tabla 2, las cantidades de tiestos seleccionados para realizar los cortes delgados $(\mathrm{N}=50)$ son: 20 fragmentos de río (40\%), 22 tiestos de laguna temporaria $(44 \%)$ y 8 de laguna permanente (16\%). De este conjunto de piezas, 18 fragmentos (36\%) son bordes, 1 corresponde a un rollo (2\%) y 31 a partes de cuerpo (62\%). En cuanto al acabado de la superficie, 12 tiestos son alisados (24\%), 15 fragmentos tienen pintura (30\%), 15 presentan incisiones (30\%), 4 tiestos muestran incisiones y pintura ( $8 \%$ ) y 4 son corrugados $(8 \%)$.

En la figura 3 se puede apreciar la composición de los materiales no plásticos de los fragmentos correspondientes a cada uno de los tres ambientes de muestreo. En cada barra la disposición del color indica la proporción media de ese mineral en los fragmentos. Las variables analizadas son: cuarzo $(\mathrm{Q})$, plagioclasa $(\mathrm{Pl})$, feldespato alcalino $(\mathrm{Fa})$, micas (biotita y muscovita) (Mi), anfíbol (hornblenda) (Anf), epidoto (Ep), hematita (Hem), magnetita (Magn), vidrio volcánico (V), fragmentos líticos (Fl) y tiesto Molido (TM). Como ya lo dijimos, en los Fl predominan las partículas de origen volcánico aunque también están presentes fragmentos de origen sedimentario y metamórfico. Dada la baja representatividad en todas las muestras de Mi, Anf y Ep se excluyeron de la representación gráfica y de los análisis posteriores. 


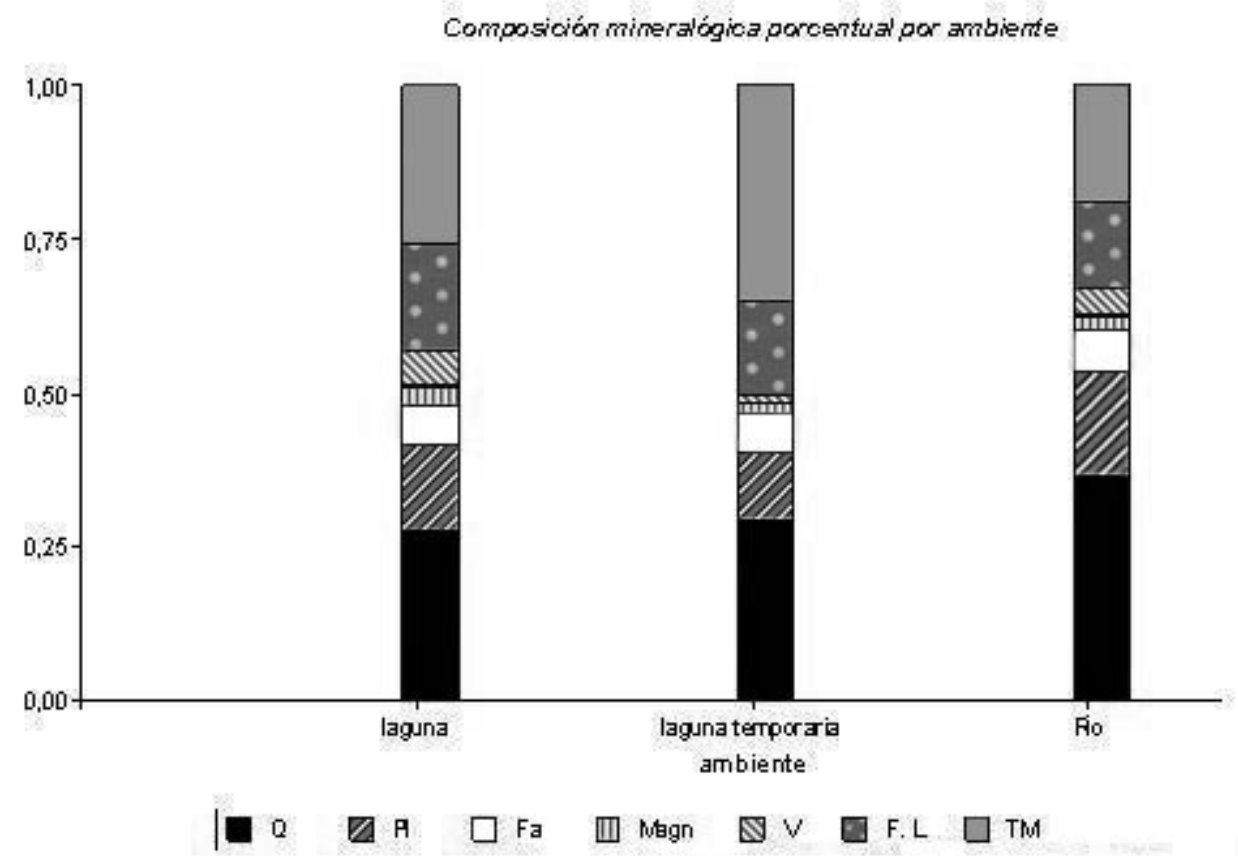

Figura 3. Composición mineralógica porcentual por ambiente

Podemos observar que en los tres ambientes predomina la presencia de Q, Pl, Fl y Fa. Sin embargo, el V se presenta en mayor proporción en laguna permanente y río que en laguna temporaria. A su vez la Magn se presenta en proporción algo mayor en río y en laguna permanente que en laguna temporaria.

Para incorporar a este estudio la interrelación entre las proporciones de los diferentes elementos mineralógicos se condujo un análisis de componentes principales, para el cual se utilizaron las variables cuantitativas estandarizadas a fin de neutralizar el efecto de las unidades de medición en el análisis. Se denomina componente principal a la combinación lineal de las variables originales que captan la mayor proporción de variabilidad posible bajo la condición de independencia en la información que cada una de ellas brinda (Cuadras 1991). El análisis realizado sobre las variables de contenido mineralógico indica que la primera componente principal logra explicar el 50\% de la variabilidad del conjunto de todas las observaciones y entre las dos primeras variables componentes principales logran explicar el $66 \%$ de dicha variabilidad.

Asimismo cabe destacar que: la primera componente principal discrimina a las piezas por la diferencia entre la presencia de tiestos molidos frente a las presencias de cuarzo, plagioclasa, fragmentos líticos y feldespato alcalino. Es decir que una pieza con un alto valor positivo en la primera componente principal, tiene alto porcentaje de TM en su composición mineralógica y bajos porcentajes de Q, Pl, Fl y Fa, mientras que una pieza con valor muy negativo indicará que tiene en su composición poco TM y mucho de los otros minerales recién mencionados. 
La segunda componente principal señala la diferencia entre la presencia de Magn y V frente a las de $\mathrm{Fa}$ y $\mathrm{Fl}$ en la composición mineralógica. En este sentido significa que una pieza con un alto valor positivo en la segunda componente principal, tiene porcentajes altos de Magn y $\mathrm{V}$, y a su vez porcentajes bajos de Fa y Fl en su composición mineralógica.

\begin{tabular}{|c|c|c|c|c|c|c|c|c|c|c|c|}
\hline MUESTRA & Q & Pl & $\mathrm{Fa}$ & Mi & Anf & Ep & Hem & Magn & v & F. L. & TM \\
\hline TCol S1 & 30 & 16 & 5 & - & 1 & ${ }^{*}$ & 1 & 1 & 5 & 25 & 15 \\
\hline TCol S2 c5 & 32 & 10 & 5 & $*$ & $*$ & $*$ & 1 & 1 & 10 & 25 & 15 \\
\hline LC 2 & 30 & 20 & 10 & - & $*$ & $*$ & 3 & 1 & 10 & 20 & 5 \\
\hline LC 3 & 18 & 10 & 5 & $\bar{*}$ & ${ }^{*}$ & $*$ & 3 & 2 & 5 & 16 & 40 \\
\hline VS A4 & $*$ & * & - & 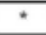 & * & $*$ & 9 & - & $*$ & 15 & 75 \\
\hline VS A2 & 36 & 20 & 10 & ${ }^{*}$ & $*$ & - & 2 & 1 & 10 & 20 & * \\
\hline LEB 1 & 40 & 22 & 10 & - & $*$ & - & 2 & $*$ & 5 & 20 & $*$ \\
\hline LT 80 & $*$ & - & * & - & $*$ & $*$ & * & $*$ & 3 & 2 & 94 \\
\hline LT 83 & 41 & 24 & 11 & ${ }^{*}$ & * & * & 2 & 1 & 5 & 10 & 5 \\
\hline LL 1 & 40 & 20 & 10 & ${ }^{*}$ & $*$ & $*$ & 2 & 1 & 6 & 20 & - \\
\hline LG1 10.897 & 38 & 18 & ${ }^{*}$ & * & $*$ & $*$ & 1 & 1 & 4 & 7 & 30 \\
\hline LG1 6.005 & 35 & 20 & 15 & * & * & * & 4 & 1 & 4 & 15 & 5 \\
\hline LG1 huaq & 30 & 13 & 4 & ${ }^{*}$ & $*$ & $*$ & 3 & $*$ & 5 & 14 & 30 \\
\hline LG1 2439 & 40 & 20 & 5 & - & $*$ & * & 1 & 2 & 3 & 25 & 3 \\
\hline LG1 N IX a & 25 & 10 & 4 & - & $\cdot$ & $*$ & 4 & 1 & 4 & 10 & 40 \\
\hline LG1 5076 & 48 & 24 & 10 & * & $*$ & * & 1 & $*$ & 6 & 10 & - \\
\hline LG4 421 & 40 & 20 & 7 & $*$ & $*$ & * & 1 & * & 6 & 20 & 5 \\
\hline LG4 1371 & 20 & 8 & ${ }^{*}$ & - & $*$ & $*$ & 3 & 1 & 2 & 5 & 60 \\
\hline LG5 1285 & 45 & 24 & 5 & ${ }^{*}$ & 1 & $*$ & 1 & * & 5 & 8 & 10 \\
\hline LG5 BIXa C10 & 30 & 15 & 4 & $*$ & $*$ & $*$ & 5 & 1 & 4 & 15 & 25 \\
\hline LG5 97 & 45 & 21 & 6 & - & $*$ & - & 1 & $*$ & 10 & 16 & - \\
\hline LG5 1.905 & 50 & 24 & 5 & ${ }^{*}$ & $*$ & ${ }^{*}$ & * & $*$ & 10 & 5 & 5 \\
\hline LG5 2.514 & 1 & * & ${ }^{*}$ & - & $*$ & $*$ & 1 & $*$ & 1 & 2 & 95 \\
\hline LG5 607 a & 40 & 20 & 8 & * & $*$ & * & 2 & 1 & 6 & 12 & 10 \\
\hline LG5 607 b & 40 & 19 & 8 & 1 & $*$ & $*$ & 2 & 1 & 6 & 12 & 10 \\
\hline LGÑ BRRS & 36 & 25 & 6 & * & $*$ & $*$ & * & 1 & 6 & 15 & 10 \\
\hline SR7 4a 2 & 25 & 18 & 4 & & $*$ & $*$ & 1 & & $*$ & 12 & 40 \\
\hline SR74a4 & $*$ & 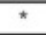 & ${ }^{*}$ & & & & 2 & & $*$ & $*$ & 98 \\
\hline SR7 4a 6 & 27 & 10 & 2 & & $*$ & & 1 & & $*$ & 40 & 20 \\
\hline SR7 4b 1 & 40 & 15 & 6 & & $*$ & & 4 & & $*$ & 20 & 15 \\
\hline SR7 4b 4 & 40 & 20 & 14 & & * & & & & $\cdot$ & 24 & 1 \\
\hline SR7 4b9 & 25 & 6 & 5 & 1 & $*$ & & 1 & 1 & $\cdot$ & 10 & 50 \\
\hline SR7 4b 12 & 20 & 5 & 3 & ${ }^{*}$ & * & ${ }^{*}$ & 2 & & $*$ & 10 & 60 \\
\hline SR7 4c 1 & 32 & 17 & 12 & * & * & * & 1 & & * & 18 & 20 \\
\hline SR7 4d 1 & 40 & 15 & 7 & & * & & 1 & & $\cdot$ & 20 & 17 \\
\hline SR7 4d 2 & 40 & 18 & 15 & * & * & & 2 & & $*$ & 15 & 10 \\
\hline SR7 35 a1 & 16 & 5 & 3 & * & $*$ & & 2 & & $*$ & 10 & 65 \\
\hline SR7 35 a2 & 35 & 14 & 8 & $*$ & $*$ & & 3 & & $*$ & 15 & 25 \\
\hline SR7 35 a3 & 18 & 10 & 3 & ${ }^{*}$ & $*$ & & 1 & & $*$ & 8 & 60 \\
\hline SR7 35 a4 & 45 & 20 & 10 & $\star$ & $*$ & & 2 & & $*$ & 20 & 3 \\
\hline SR7 35 a5 & 10 & 2 & 2 & & & ${ }^{*}$ & 1 & & $*$ & 5 & 80 \\
\hline SR7 35 c1 & 45 & 17 & 7 & * & 1 & * & 2 & 1 & $*$ & 20 & 7 \\
\hline SR7 $35 \mathrm{~d} 3$ & 15 & 3 & 4 & * & $*$ & * & 1 & & $*$ & 7 & 70 \\
\hline SR7 $35 \mathrm{~d} 4$ & 20 & 3 & 3 & * & $*$ & $*$ & 2 & 1 & $*$ & 5 & 65 \\
\hline SR7 $35 \mathrm{~d} 4$ (1) & 50 & 10 & 7 & $*$ & $\cdot$ & & 2 & 1 & 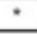 & 20 & 10 \\
\hline SR7 35 d5 & 45 & 13 & 7 & * & $*$ & & 1 & 1 & $*$ & 25 & 8 \\
\hline LP 13 & 45 & 19 & 13 & $*$ & * & & 3 & & $*$ & 20 & * \\
\hline LP 24 & 38 & 9 & 11 & & $*$ & & 2 & & $*$ & 20 & 20 \\
\hline LP 26 & 42 & 17 & 12 & & * & & 3 & & $*$ & 25 & $\star$ \\
\hline SG 16 & 35 & 14 & 9 & & $\cdot$ & & 1 & 1 & $\cdot$ & 20 & 20 \\
\hline
\end{tabular}

Tabla 4. Materiales no plásticos. Los porcentajes se refieren al 100\% de las inclusiones o carga. 


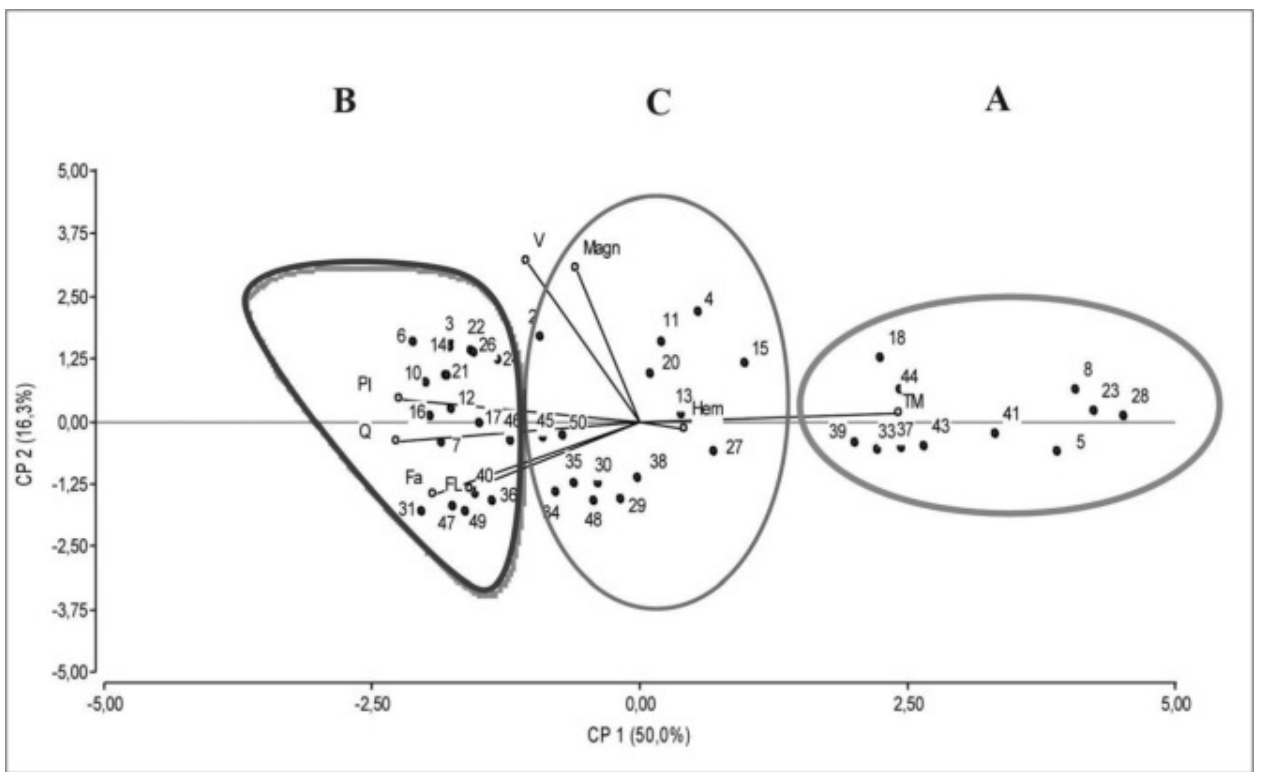

Figura 4. Análisis de componentes principales

El gráfico de la figura 4 es un biplot, es decir, un gráfico que al mismo tiempo representa a las observaciones y las variables. Las observaciones se grafican por su proyección en el plano de las componentes principales. Del gráfico de las variables se deduce su interdependencia y su variabilidad (Figura 4)

La longitud con que ha sido representada cada variable en el gráfico de biplot es proporcional a la variabilidad de la misma en este conjunto. El ángulo entre las variables representadas indica el grado de correlación entre ellas de modo que los ángulos agudos y pequeños indican alta correlación positiva, ángulos rectos indican no correlación entre las variables y ángulos obtusos indican correlaciones negativas.

Los componentes TM y Hem están correlacionados negativamente con las restantes variables, es decir que piezas con altos porcentajes de los primeros (TM y Hem) tendrán bajos porcentajes de las otras variables y recíprocamente. De este modo podemos diferenciar en el gráfico tres grupos:

\section{Grupo A:}

En este grupo la matriz es muy fina, aunque también contiene limo y arenas muy finas, de color castaño a castaño oscuro y de textura granoflotante. La matriz está compuesta por minerales de arcilla, microgránulos opacos de óxidos de hierro (hematita), vidrio volcánico (detrito fino que forma parte de la matriz), diminutos cristales máficos (anfíbol y piroxeno), material criptocristalino y los componentes de la fracción limo que se consideran parte de la matriz (cuarzo, feldespatos, litoclastos y vitroclastos). Entre las inclusiones que predominan ampliamente se encuentran los tiestos molidos, con más de $60 \%$ en la carga y en menor porcentaje la presencia de Q (5\%-20\%), Fl (5\% - 10\%), Pl (entre 3\% - 5\%) y Fa ( 0 - 4\%) (Figura 5). Consideramos que los tiestos molidos son los únicos materiales no plásticos agregados intencionalmente por el alfarero. Por los estudios realizados hasta este momento, el resto 
de las inclusiones forman parte de los sedimentos naturales. La muestra 5 (laguna Vitel) se destaca por la alta presencia de granos de hematita (9 \%) y se observa que uno de ellos tiene una granulometría de fracción arena muy gruesa.

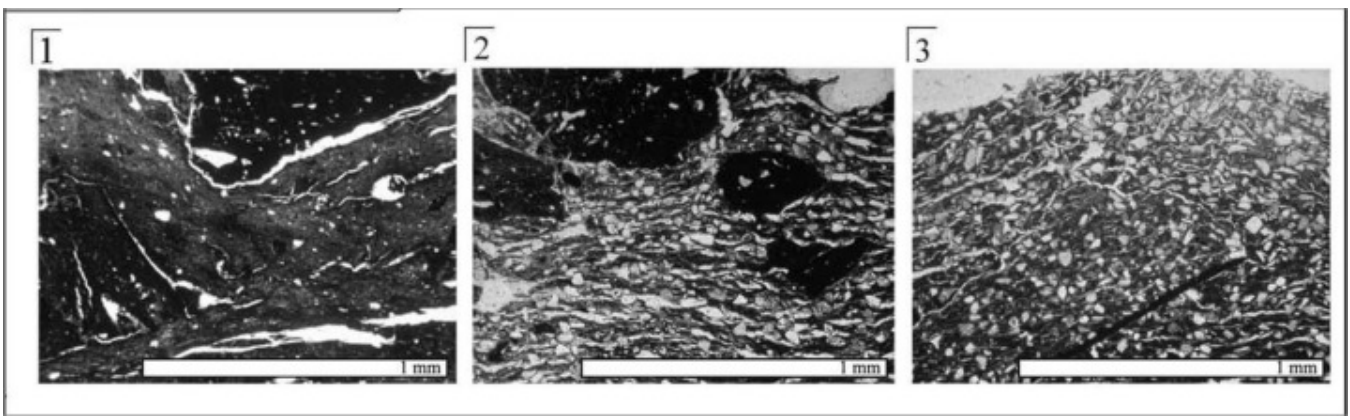

Figura 5. Fotomicrografías del Grupo A. Se destacan los tiestos molidos

\section{Grupo B}

En este grupo la matriz es de textura muy fina, aunque contiene limo y arenas finas a gruesas, predomina el color castaño oscuro. La matriz está compuesta por minerales de arcilla, microgránulos opacos de óxidos de hierro (hematita), vidrio volcánico (detrito fino que forma parte de la matriz), diminutos cristales máficos (anfíbol y piroxeno), material criptocristalino y los componentes de la fracción limo que se consideran parte de la matriz (cuarzo, feldespatos, litoclastos y vitroclastos). Entre los materiales no plásticos hallados se registra que el agregado intencional de tiesto molido es menor que en el caso del grupo A $(0-20 \%)$. En este conjunto es mayor la presencia de minerales como Q $(30 \%-50 \%), \mathrm{Pl}$ $(17 \%-25 \%), \mathrm{Fa}(6 \%-15 \%)$ y Fl $(5 \%-20 \%)$ los cuales forman parte de los sedimentos originales (Figura 6).

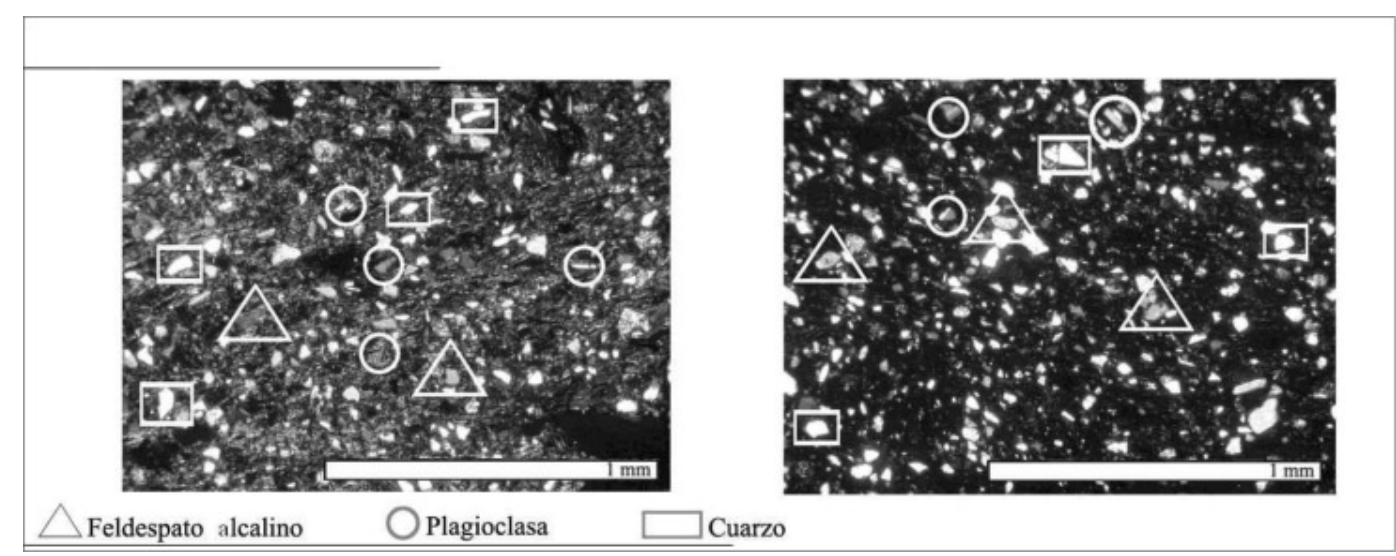

Figura 6. Fotomicrografías del Grupo B 


\section{Grupo C}

Este grupo posee una matriz de textura muy fina a mediana y predominan los colores castaño claro a castaño oscuro. Podemos apreciar que en este conjunto los componentes vidrio volcánico y magnetita, materiales no plásticos proporcionados por los sedimentos, aparecen más representados que en los grupos A y B. Ambas variables están alta y positivamente correlacionadas, es decir que piezas que contienen altos porcentajes de uno de estos minerales contienen también altos porcentajes del otro. Además en el grupo $C$, el tiesto molido muestra una presencia media ( $15 \%-25 \%)$. En cuanto a otros materiales no plásticos propios de los sedimentos, el Q está representado entre el 20\% y el $40 \%$. A su vez, los Fl presentan un porcentaje más alto que en los grupos A y B ( $16 \%-25 \%)$. También es más alta que en los otros grupos la presencia de Pl ( 9\% - 20\%) y de Fa ( 0 - 11\%) (Figura 7). $\mathrm{Al}$ interior de este grupo, la muestra 20 ( LG 5) difiere ya que tiene $5 \%$ de hematita y a su vez, la muestra 29 (SR 7) se diferencia del conjunto en general porque tiene $40 \%$ de fragmentos líticos.

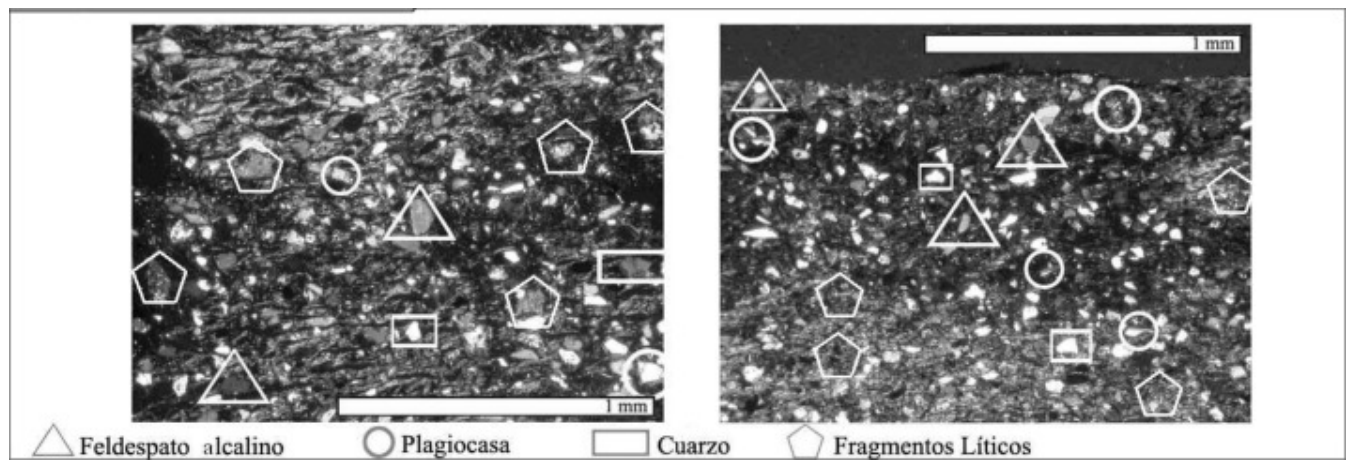

Figura 7. Fotomicrografías del Grupo C

Asimismo hemos realizado una serie de análisis para correlacionar diferentes variables. En este sentido, se vincularon los materiales no plásticos con los lugares de los asentamientos (lagunas permanentes, río o lagunas temporarias), con el acabado de la superficie, la decoración, las partes de las vasijas y el espesor de los fragmentos. Destacamos lo siguiente:

No se observan diferencias significativas entre los contenidos de Q, Pl, Fa, V, Mi, Hem, Magn, Fl, TM de los fragmentos correspondientes al borde y cuerpo de la pieza. Por lo que se asume que se utilizó la misma pasta para modelar la pieza entera.

En ninguna de las muestras de la cuenca del río Salado hemos verificado la correlación entre los componentes de las pastas y los acabados de superficie o los diferentes diseños decorativos. Los fragmentos alisados o pulidos ya sean lisos o con incisiones o pintura se encuentran dispersos entre los grupos A, B y C.

Estudiamos la relación entre el ambiente y la composición mineralógica, referido al total de los materiales no plásticos (tabla 4), encontrando que existen diferencias significativas (KW p= 0.03) en los porcentajes medianos de Pl de los fragmentos asociados a los sitios cercanos a laguna permanente, a laguna temporaria y a río. Del mismo modo se 
encontraron diferencias significativas entre los porcentajes medianos de $\mathrm{V}$ de las piezas por ambiente $(\mathrm{KW} \mathrm{p}<0.0001)$. Es mayor la presencia de plagioclasas y vidrio volcánico en las pastas de los tiestos pertenecientes a sitios cercanos al río y lagunas permanentes que en lagunas temporarias.

Con respecto a los espesores de las muestras, se estableció una clasificación de esta variable, indicando como delgados los fragmentos con espesores inferiores al primer cuartil $(<5.2 \mathrm{~mm})$, medianos los que superan el primer cuartil pero no superan el tercer cuartil $(5.2-8 \mathrm{~mm})$ y gruesos a los que superan el tercer cuartil $(>8 \mathrm{~mm})$. Estudiamos la correlación entre cada uno de los componentes de la carga y la variable espesor. Se encuentra una correlación significativa entre estas dos variables: presencia de vidrio volcánico y espesor de las paredes. Aquí el coeficiente de Spearman arroja un valor de 0.46 ( $p$ valor $=0.0012$ ). Dada la presencia de dos piezas de espesores muy superiores a las restantes, se excluyen del conjunto y se realiza un nuevo análisis de correlación resultando nuevamente significativo, es decir que no se debe a la presencia de estas dos piezas (rollo y un tiesto corrugado). Esta asociación positiva indica que piezas de mayor espesor presentan mayor proporción de $\mathrm{V}$ y recíprocamente. Lo mismo ocurre con la presencia de tiesto molido. Los resultados de la prueba de correlación de Spearman nos dan un valor de 0.44 (pvalor $=0.001$ ). Es decir, a mayor espesor mayor es el porcentaje de tiesto molido. Respecto de los demás elementos no plásticos, el espesor presenta solamente correlación levemente signficativa con la Magn $\mathrm{r}=0.28$ (pvalor $=0,06$ ) y con $\mathrm{Fa}, \mathrm{r}=-0,26$ (pvalor $=0,08$ ).

\section{Discusión}

Como se ha dicho en trabajos previos, el contexto de hallazgo de los materiales arqueológicos aquí estudiados muestra que en estos sitios una de las actividades prioritarias, quizá la principal, fue la confección de vasijas cerámicas. Tanto los sedimentos locales como la madera del monte de tala pudieron ser usados en la cadena operativa de la elaboración de esta alfarería (González 2005, González et al 2007, González y Frère 2009). A través de los estudios petrográficos de las pastas cerámicas se apreciaron sus similitudes con los sedimentos locales. Los minerales no arcillosos de los tiestos arqueológicos son coherentes con las caracterizaciones mineralógicas y granulométricas del loess pampeano ya que se reconocen la presencia de cuarzo, plagioclasa de origen volcánico, feldespato alcalino, vidrio volcánico y abundantes fragmentos líticos, fundamentalmente de origen volcánico. A su vez, como se mencionó en este trabajo, las muestras de los sedimentos analizadas corresponden a materiales finos cuya granulometría no supera el tamaño de arena fina (Figura 2a y 2b). Los minerales no arcillosos de los fragmentos arqueológicos tienen una granulometría similar, comprendida entre la fracción limo y arena muy fina y fina.

Se pudo afirmar, con respecto a los modos de hacer las vasijas en la Depresión del río Salado, que coexistieron distintas maneras de preparar las pastas. En algunos casos para mejorar las arcillas se empleó el agregado intencional de tiestos molidos (grupo A), en otros se usaron materias primas que contenían naturalmente altos porcentajes de minerales no arcillosos, fundamentalmente $\mathrm{Pl}, \mathrm{Q}, \mathrm{Fa}$ (grupo B) y finalmente emplearon otras arcillas que incluían también en forma natural valores altos de vidrio volcánico, magnetita y fragmentos líticos (grupo C).

Estas diferencias responden a los modos de preparar las pastas. Sin embargo los estudios estadísiticos realizados señalan que se usaron indistintamente cualquiera de 
estos grupos para confeccionar recipientes con diferentes acabados de superficie, ya sean alisados o corrugados. Lo mismo se observó en relación con las técnicas decorativas incisas o pintadas.

Por otro lado, para realizar vasijas de espesores mayores se observa la práctica de agregar intencionalmente tiestos molidos o usar arcillas que naturalmente presentaban porcentajes altos de vidrio volcánico. Tanto el tiesto molido como el vidrio volcánico le otorgan a la pieza una mayor resistencia y dureza, son materiales refractarios y favorecen la resistencia al impacto térmico cuando se usa el recipiente (Rice 1987; Mari 1998). A su vez, las paredes gruesas pueden ser más aptas para el almacenamiento, dado que incrementan la estabilidad y preservan la humedad dentro y fuera del recipiente. En nuestro conjunto hemos comprobado que, algunas de estas piezas con espesores de paredes más gruesos y particularmente un ejemplar con acabado de corrugado, no fue sometida al fuego y posiblemente cumplió funciones de almacenaje (González y Frère 2004). Además, las paredes gruesas, son más resistentes a los impactos propios de mezclar, batir o agitar durante la elaboración de las comidas (Rice 1987).

Asimismo, los análisis estadísticos permitieron encontrar diferencias en las composiciones mineralógicas de este conjunto de cortes petrográficos en relación con los ambientes donde fueron encontrados. De este modo pudimos realizar agrupamientos vinculados con la presencia diferencial de minerales no arcillosos. Surgió que las muestras de tiestos correspondientes a sitios que están en cercanías del río tienen menos agregado de tiesto molido. Además se encontraron diferencias significativas entre la presencia de plagioclasas y vidrio volcánico en los diferentes ambientes, siendo bastante mayor su presencia en los fragmentos de los sitios cercanos al río que en los tiestos próximos a las lagunas. Podríamos plantear que los artesanos que utilizaban arcillas cercanas al río estarían usando materias primas que no necesitarían de los agregados intencionales de tiesto molido. Esta observación abre una posibilidad para nuevos estudios que confirmen diferencias entre las arcillas de estos microambientes.

Los resultados de estos estudios ponen de manifiesto una tradición tecnológica que muestra un comportamiento en cuanto a la manufactura de la cultura material de agregar tiestos molidos en la preparación de los recipientes cerámicos. Observamos que, en la pampa bonaerense, esta tradición alfarera está más difundida en el área de la Depresión del río Salado y en la norte (De Feo et al. 1995; Perez Meroni y Blasi 1997; Pérez et al. 2009). En las áreas serrana e interserranas del sur bonaerense este patrón de manufactura no es tan representativo (Mazzanti y Porto López 2007; Madrid 1997).

En el caso del río Salado, para estos sitios de manufactura de alfarería, proponemos que la obtención de tiesto molido no representó un reto para los alfareros, ya que contaban con numerosos desechos que podían moler y agregar a las pastas para elaborar nuevas vasijas. El empleo de chamote como agregado de la pasta, además de la calidad de los sedimentos locales y la presencia de combustibles (montes de tala acompañados por molle y sauce), sostendrían el patrón de una baja movilidad residencial ya planteada para estos grupos (González y Frère 2009).

Sin duda fue una tradición en la tecnología cerámica de estos alfareros incorporar tiestos molidos, desechos culturales de vasijas elaboradas previamente. Hay autores que además de considerar el aspecto técnico funcional del empleo de tiesto molido en la preparación de la 
pasta también analizan otros aspectos, entre ellos, el simbólico. Como mencionan diversos autores que han realizado estudios etnográficos y etnoarqueológicos (DeBoer y Lathrap 1979; Chapman 2000; Gosselain 2008; Gosselain y Livingston Smith 2005) el empleo de tiesto molido es reconocido como una importante práctica social que busca hacer presente el pasado a través de la incorporación de cultura material ancestral dentro de la alfarería comúnmente utilizada.

Además del tiesto molido, en algunas muestras planteamos que se pudo haber agregado intencionalmente algún otro tipo de material no plástico. Esto lo señalamos, en el caso de la hematita porque en algunos ejemplos se observa la presencia de tamaños diferentes en los gránulos de óxido de hierro. Se plantea así, como agenda de trabajo, la busqueda de diferentes agregados en forma intencional.

Otra habilidad observada entre los alfareros del río Salado fue el buen amasado de las arcillas que se observa en el ordenamiento de los componentes de la carga y en la presencia de poros subparalelos al borde de la pieza.

Por último, con referencia a los modos de hacer las vasijas, estos cortes petrográficos aportan al conocimiento de la cocción en la tecnología alfarera del río Salado. Advertimos que todas las muestras contienen anfíbol verde -hornblenda, su presencia nos permite inferir que en la cocción de las vasijas, las temperaturas alcanzadas estuvieron por debajo de los $850^{\circ} \mathrm{C}$ (Deer et al.1992).

Las observaciones y análisis realizados en el presente trabajo nos permiten afirmar que los tres grupos de pastas reconocidos, estarían señalando elecciones en las prácticas de los alfareros, quienes manufacturaron una amplia variedad de recipientes de diversas formas y tamaños.

\section{Agradecimientos}

Las autoras agradecen la colaboración del Dr. Marcelo Zárate y a la Lic. Patricia Solá. Este trabajo se realizó en el marco de los subsidios Pict 2010- 01517 y el UBACYT 2011-2014 01/W134.

\section{Notas}

${ }^{1}$ Estudios e interpretaciones realizados por la Lic. Patricia Solá

\section{Bibliografía citada}

Bensmail, H. y G. Celeux.

1997 Inference in Model- Based cluster analysis. Statistics and Computing 7: 1-10.

Cremonte, M. B. y M. F. Bugliani.

2006-2009 Pasta, forma e iconografía. Estrategias para el estudio de la cerámica arqueológica. Xama 19-23: 239-262.

Cuadras, C. M.

1991 Métodos de Análisis Multivariante. Editorial Universitaria de Barcelona, Barcelona.

Chapman, J.

2000 Fragmentation in Archaeology. People, places and Broken objects in the prehistory of South Eastern Europe. Routledge, London. 
Dangavs, N.

1979 Presencia de dunas de arcillas fósiles en la Pampa Deprimida. Revista de la Asociación Geológica Argentina 34(1): 31-35.

2005 a La Formación La Postrera I, II, III y IV de la Laguna Las Barrancas de Chascomús, provincia de Buenos Aires. $16^{\circ}$ Congreso Geológico Argentino, Actas 4: 115-122.

$2005 \mathrm{~b}$ Los ambientes acuáticos de la provincia de Buenos Aires. Relatorio del $16^{\circ}$ Congreso Geológico Argentino 13: 219-236.

2009 Los paleoambientes cuaternarios del Arroyo La Horqueta, Chascomús, provincia de Buenos Aires. Revista de la Asociación Geológica Argentina 64 № 2: 249-262.

Dangavs, N. A. Blasi, L. Mormeneo, M. Gaillard y R. Burakosky

1991 Estudio geológico de la Laguna de Lobos. Partido de Lobos, provincia de Buenos. Aires. Centro de Investigaciones de Suelos y Aguas de Uso Agropecuario. Ministerio de Asuntos Agrarios. Provincia de Buenos Aires. MS

Dangavs, N., L. Pierrard y J. Reynaldi.

2003 Paleolimnología del río Salado entre los meridianos de $58^{\circ}$ y $60^{\circ}$, provincia de Buenos Aires. $2^{\circ}$ Congreso Argentino de Cuaternario y Geomorfología, Actas: 75-86, San Miguel de Tucumán.

Dangavs, N. y J. Reynaldi.

2008 Paleolimnología de la laguna Los Cerrillos del Medio, Monte, provincia de Buenos Aires. Revista de la Asociación Geológica Argentina 63 (1): 29-42.

De Boer, Warren y D. W. Lathrap.

1979 The Making and Breaking of Shipibo-Conibo Ceramics. Ethnoarchaeology, Implications of Ethnography for Archaeology (ed. por C. Kramer), pp. 102-138. Columbia University Press, Nueva York.

Deer, W. A., R. A. Howie y J. Zussman.

1992 An Introduction to the Rock Forming Minerals. Longman Sci, Londres.

De Feo, C., G. Balbarrey, C. Dellanegra, y V. Ithurriague.

1995 Aportes a la arqueología del litoral norbonaerense: el sitio Aspiroz. Arqueología en el Uruguay. Actas del VIII Congreso Nacional de Arqueología Uruguaya (Ed. por M. Consens, J.M López Mazz y M.C Curbelo), pp. 413-422 Editorial Surcos, Montevideo, Uruguay.

Di Rienzo J.A., F. Casanoves, M.G. Balzarini, L. Gonzalez, M. Tablada, C.W. Robledo. 2009 InfoStat. Grupo InfoStat, FCA, Universidad Nacional de Córdoba, Argentina.

Fidalgo, F., F. De Francesco y U. Colado.

1973 Geología superficial en las hojas Castelli, J.M. Cobo y Monasterio (provincia de Buenos Aires). Actas del Quinto Congreso Geológico Argentino IV: 27-39.

Francese, A.

2000 Secuencia de la experimentación cerámica en el sitio arqueológico de la Guillerma. Arqueología de la Provincia de Buenos Aires. Uso del territorio y vida cotidiana (comp.M. Isabel González), pp. 26-30 Chascomús, Argentina. 
Frère, M. M., M. I. González de Bonaveri y A. Francese.

2004 Experimentación y diseño decorativo: primeros ensayos. La región Pampeana Pampeana -su pasado arqueológico (ed. por C. Gradín y F. Oliva), pp 115-12, Laborde editor, Rosario.

Frère, M.M., M.I. González, D. Constela y C. Bayón.

2010 Experimentación con recursos actuales mediante el empleo de análisis químicos. Mamül Mapu: pasado y presente desde la arqueología pampeana (ed. por M. Berón, L. Luna, M. Bonomo, C. Montalvo, C. Aranda y M. Carrera Aizpitarte), pp.65-76, Editorial Libros del Espinillo. Ayacucho.

González Bonorino, F.

1965 Mineralogía de las fracciones arcilla y limo del Pampeano en el área de la ciudad de buenos Aires y su significado estratigráfico y sedimentológico. Revista de la Asociación Geológica Argentina XX (1): 67-148.

González de Bonaveri, M.I.

1991 Tecnología de la cerámica arqueológica del partido de Chascomús. La cadena operativa en el sitio La Guilerma 1. Arqueología 1: 105-124

González, M.I.

2005 Arqueología de alfareros, cazadores y pescadores pampeanos. Colección de Tesis Doctorales. Sociedad Argentina de Antropología, Buenos Aires.

González de Bonaveri, M. I. y M. M. Frère

2002 Explorando algunos usos prehispánicos de la alfarería pampeana. Del Mar a los Salitrales diez Mil Años de Historia Pampeana en el umbral del Tercer Milenio (ed. por D.Mazzanti, M.Berón y F. Oliva), pp 31-40 Universidad Nacional de Mar del Plata Facultad de Humanidades laboratorio de Arqueología y Sociedad Argentina de Antropología, Buenos Aires.

González M. I. y M. M. Frère

2004 Analysis of Potsherd Residues and Vessel Use in Hunter-Gatherer-Fisher Groups (Pampean Region, Argentina). Acts of XIVth UISPP Congress University of Liege: 27-36. BAR Series 1270, Oxford

2009 Talares y Paisaje Fluvial Bonaerense: Arqueología del Río Salado. Intersecciones en Antropología 10: 249-266.

2010 Diseños prehispánicos de la Alfarería pampeana. Editorial de la Facultad de Filosofía y Letras, Buenos Aires.

González de Bonaveri, M.I., M. Frère y P.Solá.

2000 Petrografías de cerámicas arqueológicas de la cuenca del río Salado, provincia de Buenos Aires. Relaciones XXV: 207-226.

González, M.I., M. M. Frère y D. Fiore

2007 Redes de Interacción en la Cuenca Inferior y Media del Salado. Arqueología en las pampas (ed. por C. Bayón, A. Pupio, M.I. González, N. Flegenheimer y M. M. Frère ), Vol 1:365-385. Sociedad Argentina de Antropología, Buenos Aires. 
González, M. I., M. M. Frére, J. Baigorria Di Scala y M. C. Squitieri.

2009 Análisis de la variabilidad cerámica en el sitio San Ramón 7. Presentado en el III Encuentro de Discusión Arqueológica del Nordeste del 24 al 27 de Junio. Libro de Resúmenes: 25-27. Santo Tomé, Santa Fe.

Gosselain, Olivier P.

2008 Mother Bella was not a Bella. Cultural Transmission and Material Culture (ed. por M.T Stark, B.J. Bowser y L. Horne), pp. 152-161. The University of Arizona Press, Tucson.

Gosselain, O. P. y A. Livingstone-Smith.

2005 The source clay selection and processing practices in Sub-Sahara Africa. Pottery manufacturing process: reconstitution and interpretation (ed. por A.L. Smith, D. Bosquet y R. Martineau), BAR Int series 1359, pp. 33-47. Arqueopress, Oxford.

Madrid, P.

1997 Análisis petrológicos y alfarería pampeana. Arqueología pampeana en la década de los '90 ( ed. por M. Berón, y G.G. Politis), pp. 61- 70. Museo de Historia Natural/ INCUAPA, San Rafael/ Olavarría.

Mari, E.

1998. Los materiales cerámicos. Buenos Aires, Librería y Editorial Alsina.

Mazzanti, D. y J. M. Porto López.

2007 Caracterización petrográfica y estructural de cerámicas de las sierras de Tandilia. Cerámicas arqueológicas. Perspectivas arqueométricas para su análisis e interpretación (ed. por M. B. Cremonte y N. Ratto), pp. 97-122. Editorial Universidad Nacional de Jujuy, San Salvador de Jujuy Pérez, M., I, Capparelli, D. Loponte, T. Montenegro y N. Russo.

2009 Estudo petrográfico da tecnologia cerâmica guarani no extremo sul de sua distribução: rio Paraná inferior e estuário do rio da Prata, Argentina. Revista da Sociedade de Arqueologia Brasileira Vol. 22, $\mathrm{N}^{\circ}$ 1: 65-82.

Pérez Meroni, M. y A. Blasi. 1997 Sitio Arqueológico "El Ancla" Provincia de Buenos Aires. Ensayo y Experimentación de sedimentos pelíticos locales para la manufactura de cerámica. Arqueología Pampeana en la década de los ‘90 ( comp. por M. Berón y G Politis). pp. 175-185. Museo de Historia Natural de San Rafael (Mendoza)/INCUAPA Olavarría.

Rice, P. M.

1987 Pottery Analysis: A Sourcebook. Chicago, University of Chicago Press.

Seber, G. A.F.

1984 Mutivariate Observations. John Wiley, New York.

Shepard, A. O.

1968 Ceramics for the Archaeologist. Carnegie Institution of Washington Publication 609, Washington, D.C. 
Solá, P.

2002 Alcances del estudio petrográfico y análisis petrológico de cerámicas arqueológicas. Ficha preparada para la cátedra de Ergología y Tecnología. MS.

Teruggi, M.

1957 The nature and origin of Argentine loess. Journal Sedimentology Petrology 27 (3): 322-332.

Tibshirani, R., G. Walther y T. Hastie.

2001 Estimating the number of clusters in a data set via the gap statistic. Journal of the Royal Statistical Society 63: 411-423.

Zárate, $\mathrm{M}$.

2009 El paisaje pampeano a través del tiempo. Mamül Mapu: pasado y presente desde la arqueología pampeana (ed. por M. Berón, L. Luna, M. Bonomo, C. Montalvo, C. Aranda y M. Carrera Aizpitarte), pp.19-32, Editorial Libros del Espinillo. Ayacucho, Argentina. 